\section{SOI: 1.1/TAS DOI: 10.15863/TAS International Scientific Journal Theoretical \& Applied Science}

p-ISSN: 2308-4944 (print) e-ISSN: 2409-0085 (online)

Year: $2018 \quad$ Issue: 02 Volume: 58

Published: $20.02 .2018 \quad$ http://T-Science.org

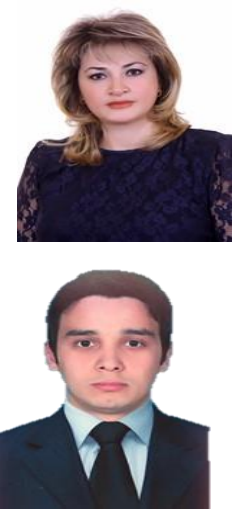

Vasila Karimbekovna Abdullaeva

Doctor of sciences in medicine,

Head of Department of psychiatry and medical psychology

Tashkent pediatric medical institute, Uzbekistan

Temur Bahodirovich Irmukhamedov

Assistant of Department of psychiatry and medical psychology

Tashkent pediatric medical institute, Uzbekistan

\title{
PREDICTORS OF FORMATION OF THE PATHOLOGICAL HOBBIES IN PATIENTS WITH PARANOID SCHIZOPHRENIA
}

Abstract: Premorbid features of patients in contrast to biological and psychosocial factors are more significant in the development of abnormal hobbies. Individual diversity of patients, activity determine the peculiarities of motivation, variety of pathological hobbies.

Key words: paranoid schizophrenia, pathological hobbies.

Language: English

Citation: Abdullaeva VK, Irmukhamedov TB (2018) PREDICTORS OF FORMATION OF THE PATHOLOGICAL HOBBIES IN PATIENTS WITH PARANOID SCHIZOPHRENIA. ISJ Theoretical \& Applied Science, 02 (58): 81-85.

Soi: http://s-o-i.org/1.1/TAS-02-58-19 Doi: crossef https://dx.doi.org/10.15863/TAS.2018.02.58.19

\section{Introduction}

The pathological hobbies are often the first signs of the debut of schizophrenia in the structure of syndrome of overvalued entities, "metaphysical intoxication", "rise of schizoid" [2, p. 205; 4, p. 657; 7, p. 15]. Occurring gradation of the abnormal hobbies are mostly descriptive in nature $[1$, p. 202; 9 , p. 220]. Pathological hobbies require careful study of the clinical structure due to the weak development of pathological qualifications, the complexity of differentiation from other abnormal disorders [3, p. $53 ; 6$, p. 435; 10, p. 570].

The relevance of the study is largely due to the significant and ambiguous influence of abnormal hobbies on the social functioning of patients [12, p. $840 ; 13$, p. $376 ; 14$, p. 85]. In connection with the above, it becomes obvious that there is a need for a more detailed study of this pathology in order to improve the diagnostic process, earlier detection of endogenous pathology $[5$, p. $245 ; 8$, p. $280 ; 11$, p. 6].

The aim of the study was to identify risk factors and conditions for the formation of pathological hobbies in patients with paranoid schizophrenia.

Material and methods: 46 patients with paranoid schizophrenia aged 20-45 years were examined by clinical and psychopathological method. All patients were examined using a specially designed scheme of the history of the disease, reflecting the specifics of the ongoing development. The assessment of premorbid personal characteristics was carried out on the basis of anamnestic data obtained from the words of the patient and his relatives. In addition to the clinical methods of examination, the results of the experimental psychological study were taken into account: the elimination of the fourth excess, the allocation of essential features, a test for classification, an icon, a personal questionnaire MMPI. The use of the PANSS scale made it possible to assess the severity of psychopathological, mainly negative symptoms.

Results and discussion: During the study, we found that the age preferred for the onset of pathological hobbies in patients with paranoid schizophrenia belonged to the period up to 29 years $(86.6 \%)$. Of these, at $11.0 \%$ of cases the development interests was in preschool, at $22.0 \%$ in primary school, $37.8 \%$ in adolescence and youth periods, and only $15.8 \%$ in adulthood. In the remaining $13.3 \%$ of observations pathological hobbies arose after 30 years. The obtained data correspond to the generally accepted opinion about the characteristic reference of hobby formation to the childhood and adolescence.

The prescription of occurrence of pathological hobbies was also analyzed. In half of the cases pathological hobbies had a prescription of occurrence from 5 years to 20 years which is testimony to their strong stability. In one third of the examined patients, the duration of abnormal hobbies ranged from 20 to 40 years, and in $9.8 \%$ of patients it was above 40 years. And only $7.3 \%$ of cases of abnormal interests 
lasted a less significant period, ranging from 1 to 4 years. The above confirms the significant stability of the studied pathological interests.

In addition to the characteristics of the age of onset and duration of the studied pathological hobbies, their interaction with the dynamics of schizophrenic spectrum disorders was assessed separately. The distribution of patients depending on the ratio of the terms of occurrence of pathological hobbies and disorders of the schizophrenic circle showed that in half of the observations pathological hobbies arose in close connection with disorders of the schizophrenic circle: shortly before the onset of the underlying disease $(21.9 \%)$, simultaneously $(6.1 \%)$ or shortly after the schizophrenic debut (24.4\%). In $37.8 \%$ of cases, abnormal hobbies were formed long before the manifestation of schizophrenic spectrum disorders. And only in $10 \%$ of patients abnormal interests appeared on the background of a long course of the underlying disease. These results confirm a generally accepted relationship between the formation of abnormal interest with the debut of schizophrenic disorders circle.

The analysis of hereditary burden on mental diseases did not find the connection between the existing dysfunctional inheritance and the formation of abnormal interests. Burdened psychopathological inheritance to a greater extent affected the development of the underlying disease than abnormal hobbies.

To clarify the conditions for the formation of abnormal hobbies, indicators were taken into account both generally favorable and immediately preceding their beginning. These included: premorbid personal characteristics, concomitant somatic and neurological deviations, features of social and family status, psychotraumatic events. The retrospective analysis allowed to distinguish three groups of factors contributing to the emergence of pathological hobbies: biological, characterological and psychosocial.

Biological factors included the presence of residual organic insufficiency in half of the observations. $17.1 \%$ of patients with this pathology was mainly congenital in nature. In the anamnesis there was heavy during pregnancy prematurity postterm or time of birth, birth by section, with stimulation, forceps, umbilical cord entanglement, low Apgar score, asphyxia. In childhood, such patients are often observed in a neurologist due to developmental delay, hyperkinetic syndrome, headaches. In $21.9 \%$ of cases there was acquired organic brain damage caused by traumatic brain injuries, meningitis, vascular diseases, severe intoxication. In $9.8 \%$ of cases - a combination of congenital and acquired residual organic insufficiency. In the remaining $51.2 \%$ of cases organic insufficiency was absent.
In all the above cases it was possible to speak only about organic insufficiency. In anamnesis patients were registered cerebro-asthenic complaints, fatigue, meteosensitivity, difficulty concentration, mild memory disorders. Patients with current, gross organic diseases of the central nervous system were excluded from the study.

Organic insufficiency acted as an additional factor that contributed to the emergence of such personal traits as rigidity, thoroughness, pedantry, a tendency to long, intense affective reactions, indirectly facilitating super valuable fixation on the object of interest. In $62.2 \%$ of patients from early childhood or later in the characterological warehouse appeared stuck radical.

$15,9 \%$ of patients had chronic somatic diseases in the compensation stage (congenital hemolytic anemia, congenital heart disease, peptic ulcer, bronchial asthma, rheumatism, chronic bronchitis). It was difficult to assess the impact of somatic pathology on the occurrence of abnormal hobbies.

Premorbid characteristics of patients are distributed in descending order as follows: schizoid $(40,2 \%)$, epileptoid $(20,7 \%)$, hyper-optimal $(15,8 \%)$, hysterical $(9,8 \%)$, mixed $(6,1 \%)$, unstable $(3,7 \%)$ and paranoid $(3,7 \%)$. In all cases premorbid personality traits did not go beyond the accentuation of character. Patients of the most widespread group of a schizoid personal warehouse, mainly male, in the childhood gave preference to creative, gambling or simple game interests which quite often became a basis for the subsequent formation of abnormal hobbies. The beginning of abnormal hobbies related to 12-15 years, long before the debut of schizophrenic spectrum disorders. In addition to abnormal hobby was typical and normal hobbies. Schizoids, characterized by a tendency to autism and fantasizing, originality, multidirectional volitional activity, his hobbies associated with the field of a kind of "art", scientific interests, "spiritual" development and collecting. It was for this group of patients was characterized by a close connection of developing pathological interest with metaphysical intoxication. Schizoid patients preferred to plunge into their unproductive, unusual up to pretentiousness hobbies in isolation, secretly from others. Despite the seemingly weak emotional intensity, indifference to the case of interest, they devoted most of their free time without long breaks for many years. The duration of pathological hobbies in schizoid patients averaged from 10 to 20 years.

Patients-epileptoid also mostly men, as children were prone to creativity, collecting and selfimprovement, which are then sometimes converted to the pathological hobby. Pathological interests of epileptoids along with the normal hobbies arose shortly before the outbreak of the underlying disease, 16-21 years old. Epileptoid patients was engaged in inventing, patiently mastered wood carving, batik 
and other types of activities that require persistence and painstaking. They continually, for decades, diligently realizing their emotionally charged, productive and traditional content hobbies. Patients with epileptoid premorbid did not tolerate the interventions of others in their private activities favorite thing, giving the reaction of dysphoria. The duration of the abnormal passions ranged from 10 to 50 years.

Hyperthymic personalities, mostly women, was dominated by the creative, scientific and sports children's hobbies, which eventually disappeared, spiraling into the pathological. Abnormal hobby the most often emerged after 30 years, simultaneously with debut disorders schizophrenic circle. Energetic, intolerant of inaction hypertime had many hobbies, including normal, easily changed, especially highlighting the art and sport. Unstable, emotionally intense anomalous interests of patients with hyperthymic warehouse was rather productive and unusual. The average duration of pathological Hobbies belonged to 10-20 years.

In persons of hysterical premorbid, more often female, popular in my childhood also enjoyed the creative, scientific and sports hobbies often then converted into the pathological. Abnormal interests were mainly formed in early childhood or matched with the heyday of the underlying disease. Abnormal hobby hysterics in the field of creativity and selfimprovement allowed them to attract the attention of others. Were noted related to the normal interests. By the nature of the morbid hobby was marginal, unusual, extravagant, bright emotionally intense, unstable. The duration of pathological hobbies in patients with hysterical warehouse ranged from 20 to 40 years.

Patients mixed personal warehouse, often men, in childhood sought mainly to scientific, less-to sports hobbies, with age gradually reduced. Their pathological interests arose preferably in 22-30 years, mainly long before the debut of the underlying disease. In addition to the morbid interests often formed and normal hobbies. Patients with mixed characterological radicals favored sport hobbies, at least - science, collecting and self-improvement. Their unusual hobby were implemented away from people, was a little emotionally meaningful and sustainable, at the same time remained quite productive. It was characterized by an average duration of 20 to 30 years.

Patients with unstable personal characteristics, male, in childhood interested in collecting, at least sports games, often becoming the basis for the pathological Hobbies. The preferred period for the deployment of painful interests was 7-11 years and slightly preceded the debut of the underlying disease. Patients unstable stock easily drawn to others in different classes, choosing a collective hobbies. Following hedonistic attitudes, gave preference to gambling. Their abnormal hobbies were not productive, traditional, unstable, weakly emotionally saturated with a duration of 20 to 30 years.

Men of paranoia type in childhood actively engaged in research and self-development disciplines, later developing into abnormal interests. The characteristic period of the beginning of pathological hobbies ranged from 7 to 21 years, often in close contact with the time of manifestation of schizophrenic spectrum disorders. Patients of paranoia type readily mastered the field of science, possessed, overcoming all obstacles, tried to introduce their "scientific research". Their morbid interests was characteristic of the conditional productivity, expressed the uniqueness of weak emotional intensity, maximum durability. The average duration of abnormal hobbies prevailed over the rest-more than $40-50$ years.

Thus, the influence of premorbid primarily reflected on the nature, the content of pathological hobbies.

Their psychosocial well-being the most frequent factor of the influence of immediate family and social environment on the development of anomal interest $(30.5 \%)$. A highly significant condition for the emergence of pathological hobbies was the impact of the immediate environment $(23.1 \%)$ - its socio-professional level $(8.5 \%)$ or existing own hobbies $(14.6 \%)$. Less often there was a direct impact on the development of abnormal hobby social environment (7.4\%). Contrary to expectations, the profession of parents, their social status rarely directly contributed to the formation of certain pathological hobbies (8.5\% of cases). Much more often, the social and educational level of the family contributed to the patients highly qualified education, the choice of appropriate activities (35.4\% of cases). In such families at least one of the parents had a higher education. In addition, families with high social status determined the content of pathological hobbies developing in patients. Most often in such families patients were supported by scientific and intellectual activities, self - improvement, lesscreativity. The data obtained were largely due to the originality, talent, personal talent, enthusiasm of the parents themselves, who encouraged the child to receive a higher level of education, diversity of its development. In $35,4 \%$ of cases, relatives had their own super valuable interests, often attracting patients with them, cultivating in families a certain occupation ("the father instilled a love for collecting coins, showed how it can be exciting", "the brother taught good music, taught to feel the harmony of sound"). These "vaccinated" patients hobbies later, in $14.6 \%$ of observations acquired the character of pathological obsession, singularity. Thus, the passion for numismatics grew into a collection of rare books, expensive collection dolls that filled the entire apartment to the dissatisfaction of relatives. 
Indulging in all patients the last money spent to replenish the little clear to others "valuable collections". Interest in music gave rise to the need for days not to leave the room, composing their own abstract, cacophonic musical compositions. In other cases, the interests cultivated by relatives disappeared or developed into ordinary hobbies as the patient grew older. No less important for the formation of special interest was the influence of the social environment: friends, neighbors, co-workers (7.4\% of cases).

Mental trauma was the second most common psychosocial factor directly or indirectly provoking the beginning of abnormal interests (9.7\% of cases). Along with the above, special attention was paid to the subjective explanation of the causes of abnormal hobby from the words of the patient. The motivation described by patients both promoted the choice of a certain kind of activity, and supported constant attraction to abnormal hobby. The most frequent option of motivation in choosing a hobby $(69.5 \%$ of cases) sounded "psychotherapeutic properties of hobby", which became an outlet, increased mood, distracted from troubles, helped "in their own compositions to splash out emotions, reflect at least some part of their rich inner world", "made it possible to communicate with others through creativity". The second motive for selecting the corresponding anomalous interest (57.3\% of cases) was fulfilling the thirst for knowledge, selfdevelopment with the "endless search for answers to the mysteries of life", "desire to make himself a man". In $13.4 \%$ of patients, pathological hobby was chosen as the main business of life. $12.2 \%$ of cases based on selection of anomalous hobby became his recreational opportunities that build physical strength, improve appearance, or conversely, the ability of the selected hobbies to be helpful to others, "to carry to others the goodness and joy". In $11.0 \%$ of cases of painful interests, attracted by the excitement, provoke the emergence of strong emotions, "grey allowed, measured, boring life to make a bright, beautiful". Less often $(6.1 \%$ of cases $)$ patients attached importance to the external, demonstrative side of pathological fascination, its possibilities of public shock, attracting the attention of others. $6.1 \%$ of patients primarily attracted material aspects, abnormal hobby was perceived by them as additional earnings.

Conclusions: Thus, attention is drawn to the conditional possibility of the influence of organic inferiority and psychosocial factors on the development of abnormal interests. Biological factors contribute to the formation of affective rigidity, thoroughness, facilitating fixation on the area of interest. Psychosocial conditions of probation provoke the appearance of abnormal hobby, largely bearing the autochthonous character. In contrast to these two factors, the characterological premorbid features are seen to be more significant in the development of abnormal hobbies. Individual diversity of patients, activity determine the peculiarities of motivation, variety of pathological hobbies.

\section{References:}

1. Akiskal KK, Savino M, Akiskal HS (2005) Temperament profiles in physicians, lawyers, managers, industrialists, architects, journalists, and artists: a study in psychiatric outpatients // J. Affect. Disord, Vol. 85(1-2), pp. 201-206.

2. Anderson SW, Damasio H, Damasio AR (2005) A neural basis for collecting behaviour in humans // Brain, Vol. 128, pp. 201-212.

3. Chambers RA, Potenza MN (2003) Neurodevelopment, Impulsivity, and Adolescent Gambling // Journal of Gambling Studies, Vol. 19 (1), pp. 53-84.

4. Evans CE, Bowman CH, Turnbull OH (2005) Subjective awareness on the Iowa Gambling Task: the key role of emotional experience in schizophrenia // J. Clin. Exp. Neuropsychol., Vol. 27, pp. 656-664.

5. Grant F, Kim S, Potenza M (2003) Paroxetine treatment of pathological gambling: a multicentre randomized controlled trial // International Clin Psychofarm, Vol.18(4), pp. 243-249.

6. Grube M (2002) Tolerance of ambiguity, art therapy and psychiatric illness // Psychiatr. Prax., Vol. 29(8), pp. 431-437.

7. Ibanez A, Blanco C, de Castro I.P, FernandezPiqueras J (2003) Genetics of pathological gambling // Journal of gambling studies, № 19 (1), pp. 11-22.

8. Langle G, Siemssen G, Hornberger S (2000) Role of sports in treatment and rehabilitation of 


\begin{tabular}{l|lr|ll|ll} 
& ISRA (India) & $=\mathbf{1 . 3 4 4}$ & SIS (USA) & $=\mathbf{0 . 9 1 2}$ & ICV (Poland) & $=\mathbf{6 . 6 3 0}$ \\
Impact Factor: & ISI (Dubai, UAE) $=\mathbf{0 . 8 2 9}$ & PUHL (Russia) $=\mathbf{0 . 2 0 7}$ & PIF (India) & $=\mathbf{1 . 9 4 0}$ \\
& GIIF (Australia) & $=\mathbf{0 . 5 6 4}$ & ESJI (KZ) & $=4.102$ & IBI (India) & $=\mathbf{4 . 2 6 0}$ \\
& JIF & $=1.500$ & SJIF (Morocco) & $=2.031$ & & \\
\hline
\end{tabular}

schizophrenic patients // Die Rehabilitation (Stuttg), Vol. 39(5), pp. 276-282.

9. Moller P, Husby R (2000) The initial prodrome in schizophrenia: searching for naturalistic core dimensions of experience and behavior // Schizophr. Bull., Vol. 26 (1), pp. 217-232.

10. Petry NM., Stinson FS., Grant BF (2005) Comorbidity of DSM-IV pathological gambling and other psychiatric disorders: results from the National Epidemiologic Survey on Alcohol and Related Conditions // J. Clin. Psychiatry.Vol. 66(5), pp. 564-574.
11. Saarinen J (2003) Nalmefene effective in the treatment of pathological gambling // Spark.№ 2, p. 6 .

12. Skokauskas N, Satkeviciute R, Burba B (2003) Psychiatric comorbidity in pathological gambling // Medicina, Vol. 9, pp. 838-844.

13. Steinbauer M, Taucher J (2001) Paintings and their progress by psychiatric inpatients within the concept of integrative art therapy // Wiener Medizinische Wochenschrift., Vol. 151, pp. 375-379.

14. Zapotoczky HG (2005) Poetry and schizophrenia // Fortschritte der NeurologiePsychiatrie, Vol. 73, pp. 84-87. 